\title{
Research Paper: Effect of an Eight-week Core Stabil- ity Training Program on the Functional Movement Screen Test Scores in Elite Goalball Players
}

\author{
Azadeh Mahrokh Moghadam¹ (D), Mostafa Zarei²* (D), Fariba Mohammadi ${ }^{3}$ (D) \\ 1. Department of Sports Injuries and Corrective Exercise, Faculty of Physical Education and Sports Sciences, Karaj Branch, Islamic Azad University, \\ Karaj, Iran. \\ 2. Department of Sport Rehabilitation and Health, Faculty of Sport Sciences and Health, Shahid Beheshti University, Tehran, Iran. \\ 3. Department of Sport Injuries and Corrective Exercises, Sports Medicine Research Center, Sport Sciences Research Institute, Tehran, Iran.
}

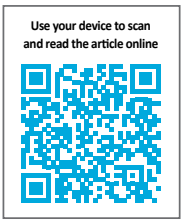

Citation Mahrokh Moghadam A, Zarei M, Mohammadi F. Effect of an Eight-week Core Stability Training Program on the Functional Movement Screen Test Scores in Elite Goalball Players. Physical Treatments. 2021; 11(1):55-62. http://dx.doi. org/10.32598/ptj.11.1.455.1

http://dx.doi.org/10.32598/ptj.11.1.455.1

Article info:

Received: 08 Apr 2020

Accepted: 08 Sep 2020

Available Online: 01 Jan 2021

\section{Keywords:}

Core stability, Screening, Motor function, Goalball

\section{A B S T RA C T}

Purpose: This study aimed to investigate the effect of eight weeks of core stability training on the Functional Movement Screen (FMS) test scores in elite goalball players.

Methods: The study sample included 26 elite goalball players. The players were randomized into the two groups of experimental $(n=13)$ and control $(n=13)$. Besides, FMS was used to evaluate the study variables in both groups, before and after the eight weeks of training. After the pretest, the experimental group performed the core stability training using a Swiss ball, three days a week for eight weeks; the control group did the usual training. Then, the analysis of covariance at the significant level of 0.05 was used to analyze the obtained data.

Results: The results showed a significant difference in the adjusted mean scores of the FMS test between the experimental and control groups $(\mathrm{P}=0.021)$.

Conclusion: The positive effect of core stability training on the FMS test scores of the motor function in goalball players emphasizes the effectiveness of this training in core stability muscles. Therefore, it is suggested to use core stability training combined with exercises as an effective way to improve movement patterns and prevent injury in goalball players. 


\section{Highlights}

- Little is known about how core stability impacts movement screen test in blind athletes.

- Eight weeks of core stability exercise can positively affect FMS test in elite Goalball players.

- The advantages are more noticeable in Goalball players with lower movement quality.

\section{Plain Language Summary}

Preparticipation assessments are the standard approach for evaluating poor movement quality that would increment musculoskeletal injury chance. However, little is known about how core stability impacts movement screen test in blind athletes. This study examined the effects of the an 8-week core stability training program on the functional movement screening test in 26 elite goalball players (13 in the training group, 13 in the control group). The training group was requested to complete a core stability training program using a swiss ball that met 3 times per week for 8 weeks. The control group did usual goalball exercises. The score of functional movement screening test were significantly increased from the baseline in training group. An 8-week core stability training program using a swiss ball increases functional movement screening test in Iranian elite goalball players. The advantages are more noticeable in goalball players with lower movement quality.

\section{Introduction}

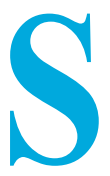

tudies have shown that elite goalball athletes need the explosive strength of lower and upper limbs, speed, balance, muscular strength, and high muscular endurance $[1,2]$. Also, coaches use several types of training to improve the performance of goalball players. Recently, many studies have examined the effect of core stability training on the motor function of athletes in various fields and reported the positive effects of this training [3]. However, the effect of this training on the motor function of goalball players is not clear.

With the eyes closed, the body fluctuations of a healthy person in the standing position increase by $20 \%$ to $70 \%$, compared with when the eyes are open $[4,5]$. Vision is also of particular importance in motion control and balance and is often more important and prominent than the other sources of information $[6,7]$. The reduction or loss of function in the systems involved in height control weakens the performance of the other height control mechanisms. Besides the changes in height control, the lack of vision increases social dependence, limits daily activities, decreases self-confidence, and declines physical fitness [8]. Study on the frequency of sports injuries in the veteran and disabled athletes of twelve sports (athletics, sitting volleyball, weightlifting, wheelchair basketball, shooting, amputee football and cerebral palsy football, archery, table tennis, swimming, cycling, and goalball) showed the highest frequency of injuries in volleyball [9]. Therefore, it is important to identify the causing and risk factors of injuries in goalball. The preseason screening of athletes is used to identify the risk factors of injuries [10]. Moreover, the enhancement of core stability and the strengthening of core stabilizing muscles has become one of the new topics in sports medicine. Core stability enhancement has several advantages, including improved athletic performance, the prevention of injuries, and the reduction and treatment of musculoskeletal disorders [11]. Also, core stability training improves athletic performance and reduces injury [12].

Goalball is one of the sports that was invented in 1946 by Hanz Lorenzen to help in the rehabilitation and improvement of the physical and mental fitness of the blinded people. It has been played since Toronto Paralympics in 1976. Currently, 112 countries are the members of the Blind Sports Federation and play goalball. In this sport, players compete in two teams of three. The players of each team try to roll a ball $(1.250 \mathrm{~kg})$ towards the opposing team's net [13].

The pelvic and trunk stability is essential for all upper and lower-limb movements, also, trunk muscles are activated before the limb muscles to stabilize the spine as a structure for functional movements [14]. This area acts as a link to perform sports by effectively transferring the forces produced in the lower limb to the upper limb through the trunk $[3,15]$. Besides, core stability plays a pivotal role in the effective biomechanical performance 
Table 1. Core stability training program for eight weeks

\begin{tabular}{|c|c|c|c|c|c|c|c|c|c|}
\hline \multirow{2}{*}{ Training Protocol } & \multicolumn{2}{|c|}{ First and Second Weeks } & \multicolumn{2}{|c|}{ Third and Fourth Week } & \multicolumn{2}{|c|}{ Fifth and Sixth Weeks } & \multicolumn{2}{|c|}{ Seventh and Eighth Weeks } & \multirow{2}{*}{ Resting } \\
\hline & Sets & Repetitions & Sets & Repetitions & Sets & Repetitions & Sets & Repetitions & \\
\hline $\begin{array}{l}\text { Lifting the opposite arm } \\
\text { and leg on the ball }\end{array}$ & 2 & 6 & 2 & 8 & 3 & 6 & 3 & 8 & 30 \\
\hline Push-up on the ball & 2 & 6 & 2 & 8 & 3 & 6 & 3 & 8 & 30 \\
\hline Single-leg crunch & 2 & 6 & 2 & 8 & 3 & 6 & 3 & 8 & 30 \\
\hline Stability ball squat & 2 & 6 & 2 & 8 & 3 & 6 & 3 & 8 & 30 \\
\hline Ball hamstring curls & 2 & 6 & 2 & 8 & 3 & 6 & 3 & 8 & 30 \\
\hline Cycling & 2 & 7 & 2 & 10 & 3 & 13 & 3 & 16 & 30 \\
\hline Lounge using stability ball & 2 & 8 & 2 & 10 & 3 & 8 & 3 & 10 & 30 \\
\hline Side-lying external rotation & 2 & 8 & 2 & 10 & 3 & 8 & 3 & 10 & 30 \\
\hline Single-leg bridge & 30 & 2 & 35 & 2 & 45 & 2 & 55 & 2 & 30 \\
\hline Side plank & 30 & 2 & 35 & 2 & 45 & 2 & 55 & 2 & 30 \\
\hline
\end{tabular}

and is an important component in the maximum efficiency and performance of athletes and the prevention of sports injury. The core of the body is the endpoint, the point of connection, and the receptor of forces from all motor chains during all dynamic activities, including sports activities. Therefore, the control of the strength, balance, and movement of this part will maximize the function of the kinetic chain of the upper and lower limb [16]. Although many studies have examined the effect of core stability training on the motor function of athletes in various fields, no study has examined the effect of this type of training on the motor function of goalball players.

On the other hand, a Functional Movement Screen (FMS) seems necessary to prevent injury and improve performance strategies [10]. Cook, Burton, and Hoogenboom have introduced the FMS tests, considering preseason screening and performance-related factors [17]. The FMS includes seven motor performance tests, which can identify limitations and changes in normal movement patterns. These tests are designed to investigate the interaction between kinetic chain mobility and the needed stability to perform functional and essential motor patterns. It takes five to ten minutes to be performed, thus, the FMS tests can be easily used by trainers for preseason assessments $[17,18]$. The movement patterns of these tests require controlled neuromuscular movement in various sports. By adapting to dysfunctional movement strategies, athletes are at the risk of injury, despite performing well in sports [10]. Due to the participation of players with vision loss in goalball as well as weakness in their posture, the movement patterns of these players are also affected [8]. Changes in movement patterns also cause compensatory movement patterns, muscle strain, overwork, and ultimately injury [19]. Accordingly, screening the motor performance of goalball players is of great importance.

Various studies have shown that defects in the core stability can reduce the effectiveness of correct movement patterns. However, no study has yet examined the effect of core stability training on the motor performance of goalball players. Therefore, this study investigated the effect of eight weeks of core stability training on the FMS scores of goalball players, in Tehran and Qazvin City.

\section{Materials and Methods}

The study sample consisted of 26 elite goalball athletes with B2 and B3 visual classification. Using the purposeful sampling method, the players were selected and randomly assigned into the two groups of experimental $(n=13)$ and control $(n=13)$. Also, two subjects of the control group and two of the experimental group were excluded from the study, because of the lack of regular participation in the training sessions and tests. The experimental group was subjected to the core stability training in three 40-minute sessions per week, for eight weeks. The training sessions were adopted from three studies that reported the effectiveness of this type of training. Besides, we considered a 30 -second interval between each set, also, a resting time of $60 \mathrm{~s}$ was re- 
Table 2. Mean $\pm S D$ of the demographic characteristics of the study sample $(n=13)$

\begin{tabular}{cccc}
\hline & \multicolumn{2}{c}{ Mean \pm SD } & P \\
\cline { 2 - 4 } Demographic Characteristics & Experimental & Control & 0.22 \\
\hline Height $(\mathrm{cm})$ & $168.23 \pm 10.95$ & $173.53 \pm 10.72$ & 0.65 \\
\hline Weight $(\mathrm{kg})$ & $73.61 \pm 13.20$ & $71.30 \pm 12.51$ & 0.41 \\
\hline BMI $\left(\mathrm{kg} / \mathrm{m}^{2}\right)$ & $25.84 \pm 2.75$ & $23.56 \pm 2.65$ & \\
\hline
\end{tabular}

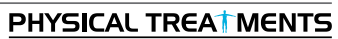

Table 3. Results of the ANCOVA

\begin{tabular}{|c|c|c|c|c|c|c|}
\hline \multicolumn{7}{|c|}{ The Analysis of Covariance } \\
\hline & Pretest & df & Mean Square & $\mathbf{F}$ & $\mathbf{P}$ & $\eta 2$ \\
\hline \multirow{2}{*}{ Functional movement screen } & Training & 1 & 1.69 & 6.13 & 0.021 & 0.21 \\
\hline & Error & 23 & 0.277 & - & - & - \\
\hline
\end{tabular}

PHYSICAL TREA $\ M E N T S$

garded between two different movements [20-22] (Table 1). Concurrently, the control group performed the usual training. Finally, the FMS tests were used to evaluate the study variables. Also, SPSS v. 22 was used to analyze the obtained data. A significance level of 0.05 was considered in all statistical analyses.

\section{Performing and Scoring of the FMS Tests}

Subjects were scored 3 if they correctly and without compensatory movements performed tests, including the deep squat, stepping over the obstacle, lounge, shoulder flexibility, active straight leg raise, trunk stability pushup, and rotary stability. They were scored 2 if they performed the tests with compensatory movements. Those who were unable to perform the movement without compensatory movements were scored 1 , and the subjects received no score in the case of the feeling of pain during movement or test [23] (Figure 1-7).

\section{Results}

According to Table 2, the two groups do not significantly differ in the demographic information, such as age, weight, height, and body mass index.

The analyses confirmed the normal distribution of data, the homogeneity of regression line slope, and the linear relationship between the covariate and dependent vari-

Figure 1. Deep Squat-test

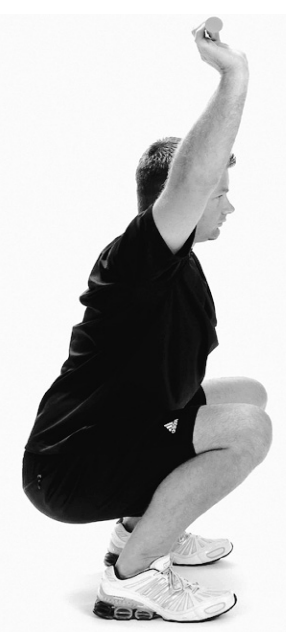

PHYSICAL TREA $\$ MENTS 


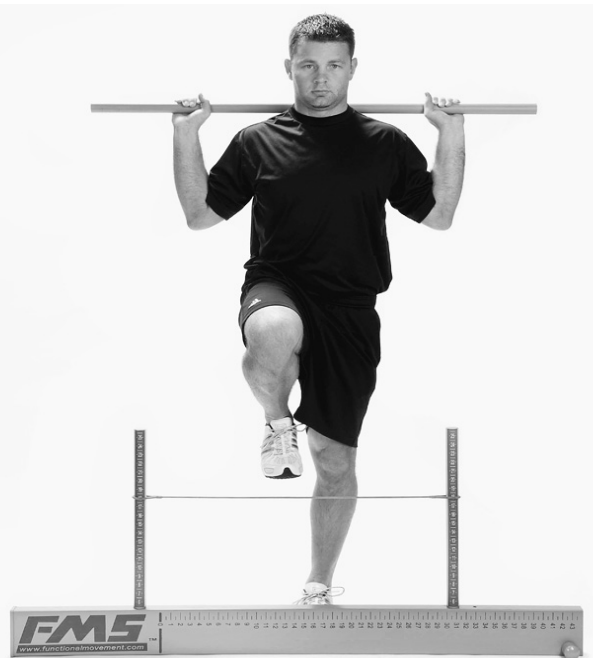

Figure 2. Hurdle step

able. Therefore, the Analysis of Covariance (ANCOVA) at the level of 0.05 was used to test the hypotheses.

The results of ANCOVA showed a significant difference between the adjusted mean of the FMS scores between the core stability training $(\mathrm{M}=16.72)$ and control $(\mathrm{M}=16.2)$ groups of elite athletes $\left(\mathrm{F}_{1,23}=6.13, \mathrm{P}=0.021\right.$, and $\left.\eta^{2}=0.21\right)$ (Table 3).

\section{Discussion}

Our results showed that core stability training improved the score of the FMS test in goalball athletes. The movement patterns of these players are affected because of the vision loss and postural weakness [8]. Moreover, changes in movement patterns cause compensatory movement patterns, muscle strain, overwork, and ultimately injury

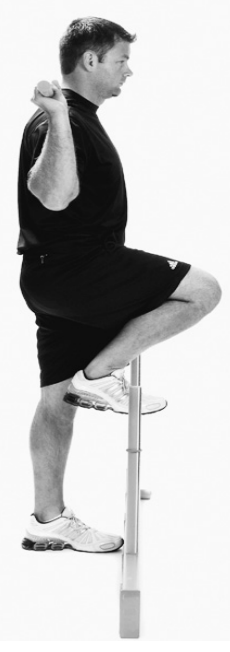

PHYSICAL TREA TMENTS

[19]. Defects in core stability can reduce the effectiveness of correct movement patterns [24]. Besides, deficiencies in the core stability muscles lead to a delay in the activation of the muscles of the lower extremities and different injuries. These muscles are also responsible for maintaining the pelvic floor height. Thus, the weakness of these muscles leads to the loss of proper pelvic alignment, therefore, the muscles of the lower limbs that are attached to this area reduce their efficiency and are prone to injury due to the disruption of the proper length-tension relationship [16].

The most important functions of the core stability muscles include providing proper alignment, the optimal connection between the pelvis and the spine, the prevention of excessive pressure, and compensatory pelvic movements throughout the limbs [25]. Thus, core
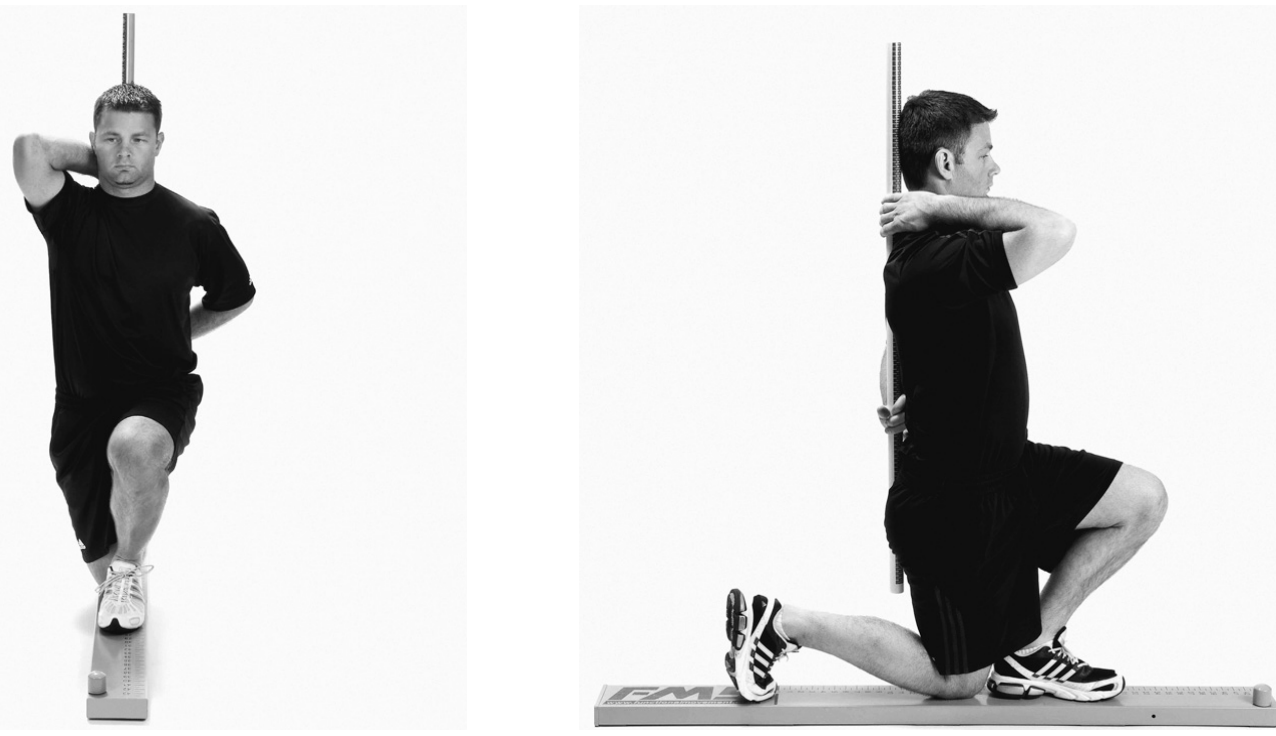

Figure 3. In-line lunge

PHYSICAL TREA $\$ MENTS 


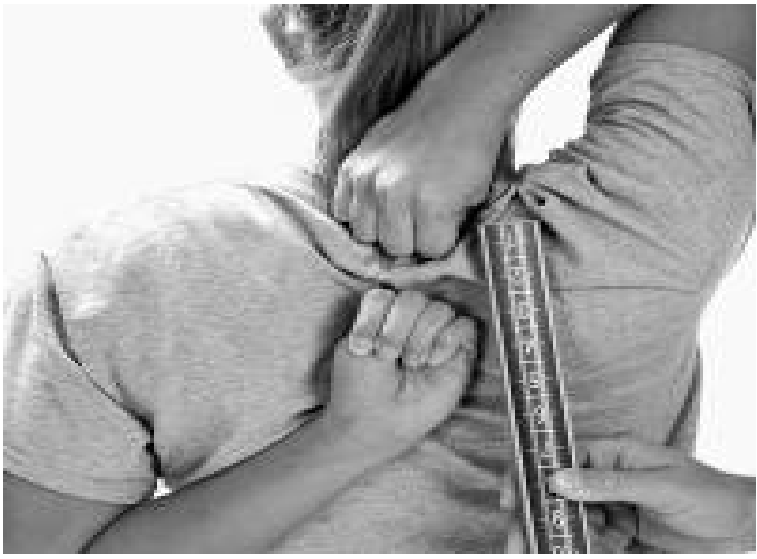

Figure 4. Shoulder Mobility

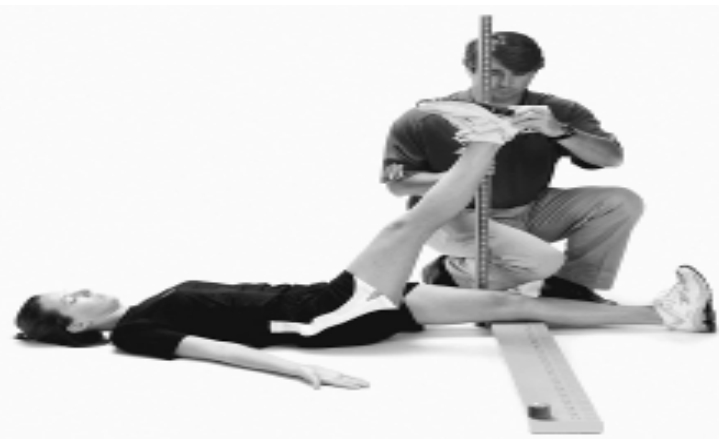

Figure 5. Active straight leg raise

stability training prevents injury. Our results confirm this statement because FMS is a method to predict the percentage of injury, also, poor core stability is one of the factors affecting the rate of injury in female athletes [11]. Consistent with the results of Haddadnejad et al. [11], our results indicate the effectiveness of core stability training in the FMS score.

Besides, Babakhani et al. stated that training to improve core stability muscle can be used as a way to prevent injury [12]; this is consistent with our results, regarding the effect of core stability training on the score of the FMS test. Also, regarding the effect of core stability train-

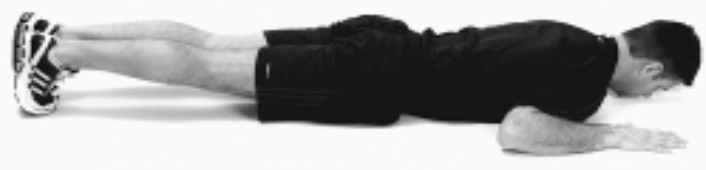

Figure 6. Truck Stability Push Up

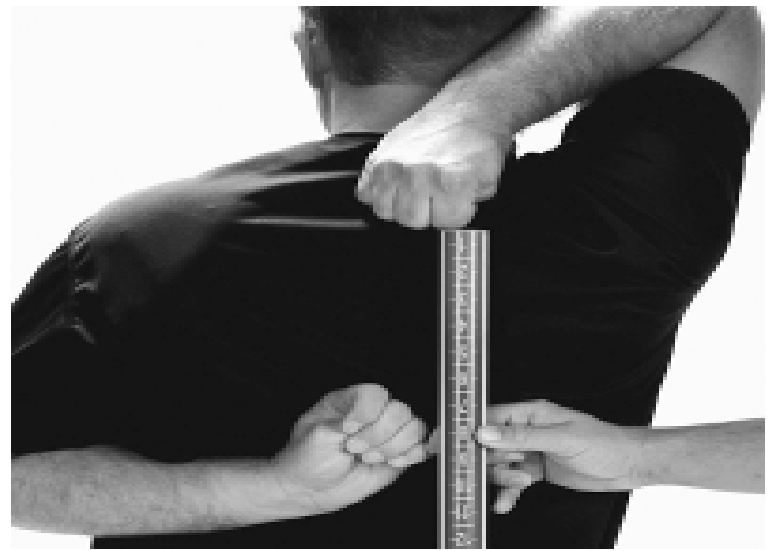

PHYSICAL TREATMENTS

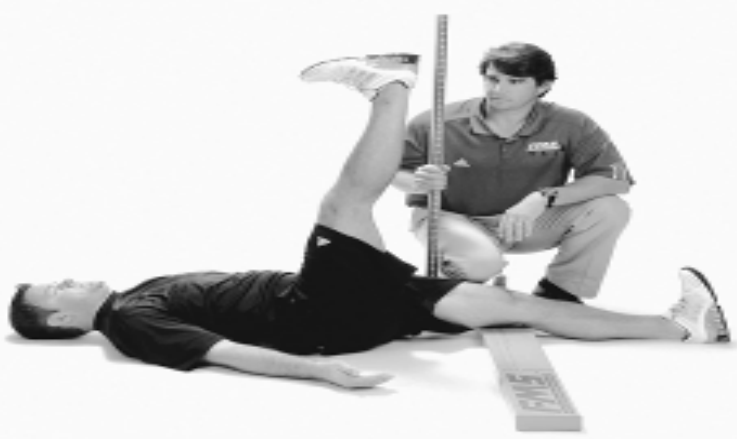

PHYSICAL TREATMENTS

ing on the score of FMS, our results are consistent with the results of Kibler et al. who stated that core stability training plays a pivotal role in the effective biomechanical performance and is an important factor for maximal function and performance and the prevention of injuries in athletes [16]. Because FMS is a method to predict the percentage of injury. However, Okada et al. examined the "relationship between core stability, motor function, and performance" and reported no significant relationship between core stability training and the FMS test scores [26]. The discrepancy between the two studies could be derived from the consideration of the different study samples because Okada et al. studied on nonathletes.

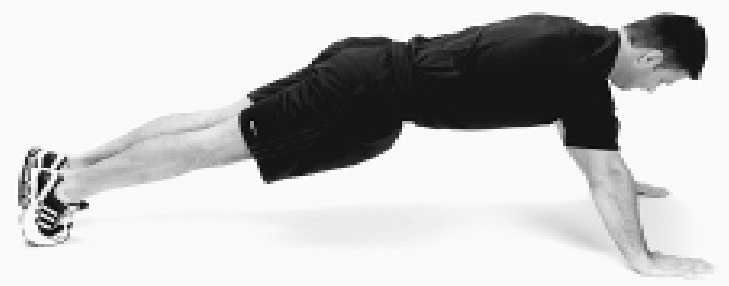

PHYSICAL TREATMENTS 


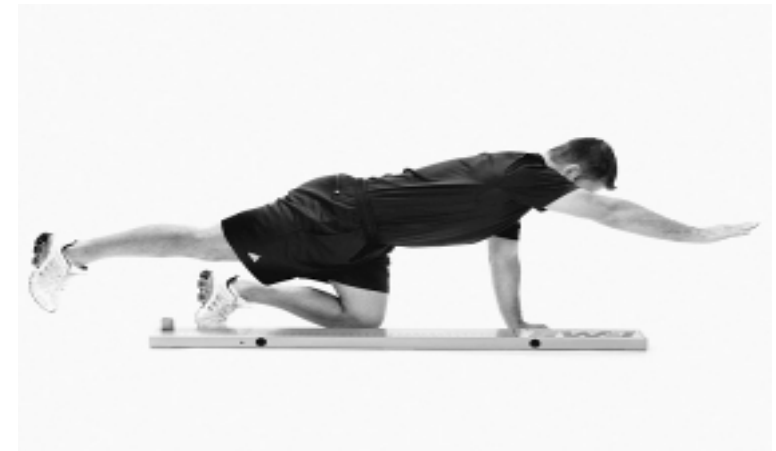

Figure 7. Rotary Stability

The positive effect of core stability training on the FMS test scores and the motor function of goalball players emphasizes the constructive effect of this training on core stability muscles. Because the core of the body is the endpoint, the point of connection, and the receptor of force from all motor chains during all dynamic activities. Therefore, the control of the strength, balance, and movement of this part will maximize the function of the kinetic chain of the upper and lower limb [16]. Also, this area acts as a link to perform sports by effectively transferring the forces produced in the lower limb to the upper limb through the trunk [21].

\section{Conclusion}

Defects in the stability muscles reduce the strength of the muscles responsible for the kinetic chain, increase the reaction time, reduce the ability to maintain balance and the center of gravity within the support surface; weakness in these muscles makes a person prone to injury [24]. Due to the significant positive relationship obtained between core stability training and the FMS test scores, it is recommended to use core stability training along with other trainings as an effective way to improve athletic performance and balance and prevent injury.

\section{Ethical Considerations}

\section{Compliance with ethical guidelines}

This study was approved by the Faculty of Physical Education \& Sport Sciences, Islamic Azad University, Karaj Branch committee and all procedures performed in studies involving human participants were in accordance with the ethical standards of the institutional and with the 1964 Helsinki declaration and its later amendments or comparable ethical standards. Informed consent was obtained from all individual participants included in the study.

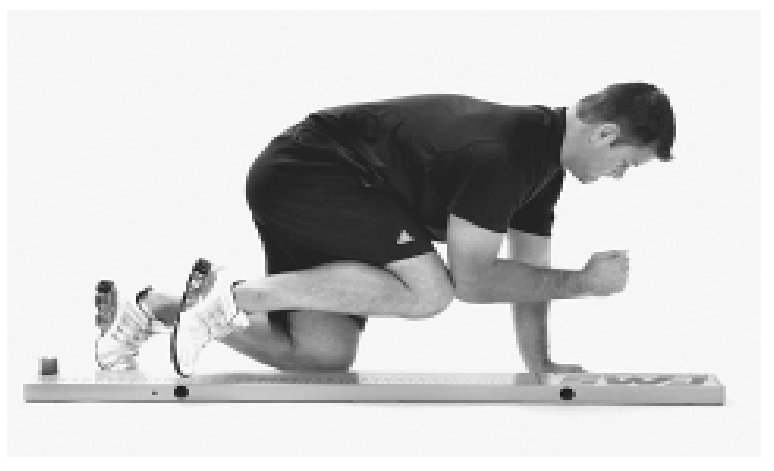

PHYSICAL TREATMENTS

Funding

This research did not receive any grant from funding agencies in the public, commercial, or non-profit sectors.

\section{Authors' contributions}

All authors equally contributed to preparing this article.

\section{Conflict of interest}

The authors declared no conflict of interest.

\section{References}

[1] Karakaya IC, Aki E, Ergun N. Physical fitness of visually impaired adolescent goalball players. Perceptual and Motor Skills. 2009; 108(1):129-36. [DOI:10.2466/pms.108.1.129-136] [PMID]

[2] Molik B, Morgulec-Adamowicz N, Kosmol A, Perkowski K, Bednarczuk G, Skowroński W, et al. Game performance evaluation in male goalball players. Journal of Human Kinetics. 2015; 48(1):43-51. [DOI:10.1515/hukin-2015-0090] [PMID] [PMCID]

[3] Hibbs AE, Thompson KG, French D, Wrigley A, Spears I. Optimizing performance by improving core stability and core strength. Sports Medicine. 2008; 38(12):995-1008. [DOI:10.2165/00007256-200838120-00004] [PMID]

[4] Cheng K. A systematic perspective of postural control [MSc thesis]. Toronto: University of Toronto; 2004. https:/ / www. semanticscholar.org/paper/A-Systematic-Perspective-ofPostural-Control-Cheng-Cheng/d8ebc041f67199db3f28ad$5329619073322 \mathrm{~d} 7 \mathrm{~d} 3 \mathrm{a}$

[5] Paul M, Biswas SK, Sandhu JS. Role of sports vision and eye hand coordination training in performance of table tennis players. Brazilian Journal of Biomotricity. 2011; 5(2):106-16. https://web.b.ebscohost.com/abstract?direct=true\&p rofile $=$ ehost \&scope $=$ site \&authtype $=$ crawler\&jrnl

[6] Berencsi A, Ishihara M, Imanaka K. The functional role of central and peripheral vision in the control of posture. $\mathrm{Hu}-$ 
man Movement Science. 2005; 24(5):689-709. [DOI:10.1016/j. humov.2005.10.014] [PMID]

[7] Bhambhani Y. Overview of physical training in athletes with disabilities: Focus on long term athlete development. [MSc. thesis]. Alberta: University of Alberta; 2010.

[8] Soares AV, Oliveira CSRd, Knabben RJ, Domenech SC, Junior B, Gomes N. Postural control in blind subjects. Einstein (São Paulo). 2011; 9(4):470-6. [DOI:10.1590/s167945082011ao2046] [PMID]

[9] Shojaei H, Sokhangoei Y, Soroush M, Forouzan A, Modirian $\mathrm{E}$, Nejati $\mathrm{V}$. [Evaluation of sport injury incidence in veterans and disabled athletes during MILAD-e-KOWSAR festival in Tehran (Persian)]. Iranian Journal of War and Public Health. 2009; 1(3):25-36. http:/ /ijwph.ir/article-1-33-fa.html

[10] Chorba RS, Chorba DJ, Bouillon LE, Overmyer CA, Landis JA. Use of a functional movement screening tool to determine injury risk in female collegiate athletes. North American Journal of Sports Physical Therapy. 2010; 5(2):47-54 [PMID] [PMICD]

[11] Hadadnezhad M, Rajabi R, Alizadeh MH, Letafatkar A. [Does core stability predispose female athletes to lower extremity injuries? (Persian)] Journal of Research in Rehabilitation Sciences. 2011; 6(2):88-9. http://jrrs.mui.ac.ir/index. $\mathrm{php} /$ jrrs/article/view/125

[12] Babakhani F, Oladghobadi K, Fatahi F. [The effect of core muscle fatigue on static and dynamic balance and endurance of athletic women (Persian)]. Scientific Journal of Kurdistan University of Medical Sciences. 2015; 20(4):65-72. [DOI:10.22102/20.4.65]

[13] Çolak T, Bamaç B, Aydin M, Meriç B, Özbek A. Physical fitness levels of blind and visually impaired goalball team players. Isokinetics and Exercise Science. 2004; 12(4):247-52. [DOI:10.3233/IES-2004-0182]

[14] Hodges PW, Richardson CA. Contraction of the abdominal muscles associated with movement of the lower limb. Physical Therapy. 1997; 77(2):132-42. [DOI:10.1093/ptj/77.2.132] [PMID]

[15] Samson KM. The effects of a five-week core stabilizationtraining program on dynamic balance in tennis athletes [MSc. thesis]. Morgantown: West Virginia University; 2005. https:// search.proquest.com/openview/6566ad2d8d89fe1 0c0797b81963e4f87/1?pq-origsite=gscholar\&cbl=18750\&di $\mathrm{ss}=\mathrm{y}$

[16] Kibler WB, Press J, Sciascia A. The role of core stability in athletic function. Sports Medicine. 2006; 36(3):189-98. [DOI:10.2165/00007256-200636030-00001] [PMID]

[17] Cook G, Burton L, Hoogenboom B. Pre-participation screening: The use of fundamental movements as an assessment of function-part 1. North American Journal of Sports Physical Therapy. 2006; 1(2):62-72. [PMID] [PMICD]

[18] Sorenson EA. Functional movement screen as a predictor of injury in high school basketball athletes [PhD dissertation] Eugene: University of Oregon; 2009. http://hdl.handle. net/1794/10594

[19] O'connor F, Deuster P, Davis J, Pappas C, Knapik J. Functional movement screening: Predicting injuries in officer candidates. Medicine and Science in Sports and Exercise.
2011; 43(12):2224-30. [DOI:10.1249/MSS.0b013e318223522d] [PMID]

[20] Stanton R, Reaburn PR, Humphries B. The effect of short-term Swiss ball training on core stability and running economy. The Journal of Strength \& Conditioning Research. 2004; 18(3):522-8. [DOI:10.1519/00124278-200408000-00023] [PMID]

[21] Kahle N. The effects of core stability training on balance testing in young, healthy adults [Bs. thesis]. Toledo: University of Toledo; 2009. https://www.semanticscholar.org/ paper/

[22] Sekendiz B, Cug M, Korkusuz F. Effects of Swiss-ball core strength training on strength, endurance, flexibility, and balance in sedentary women. The Journal of Strength \& Conditioning Research. 2010; 24(11):3032-40. [DOI:10.1519/ JSC.0b013e3181d82e70] [PMID]

[23] Cook G. Movement: Functional movement systems: Screening, assessment and corrective strategies. Santa Cruz: On Target Publications; 2010. https://books.google.com/ books?id=iOadmwEACAAJ\&dq

[24] Zazulak BT, Hewett TE, Reeves NP, Goldberg B, Cholewicki J. Deficits in neuromuscular control of the trunk predict knee injury risk a prospective biomechanical-epidemiologic study. The American Journal of Sports Medicine. 2007; 35(7):1123-30. [DOI:10.1177/0363546507301585] [PMID]

[25] Nadler SF, Malanga GA, Bartoli LA, Feinberg JH, Prybicien M, DePrince M. Hip muscle imbalance and low back pain in athletes: Influence of core strengthening. Medicine \& Science in Sports \& Exercise. 2002; 34(1):9-16. [DOI:10.1097/00005768-200201000-00003] [PMID]

[26] Hadadnezhad M, Rajabi R, Alizadeh M, Letafatkar A. [Does core stability predispose female athletes to lower extremity injuries? (Persian)] Research in Rehabilitation Sciences. 2010; 6(2):89-98. http://jrrs.mui.ac.ir/index.php/ jrrs/article/view/125

[27] Okada T, Huxel KC, Nesser TW. Relationship between core stability, functional movement, and performance. The Journal of Strength \& Conditioning Research. 2011; 25(1):252-61. [DOI:10.1519/JSC.0b013e3181b22b3e] [PMID] 